\title{
Deterioration of Extra Virgin Olive Oil Caused by Different Processes
}

\author{
Nadia Segura $^{1}$, Yenny Pinchak ${ }^{1}$, Natalie Merlinski ${ }^{1}$, Miguel Amarillo ${ }^{1}$, Camila Feller $^{1}$, Bruno Irigaray $^{1}$, Laura \\ Raggio $^{1}$, Mariana Oroño ${ }^{1} \&$ María A. Grompone ${ }^{1}$ \\ ${ }^{1}$ Área de Grasas y Aceites, Facultad de Química, UdelaR, Gral Flores 2124, CP 11800, Montevideo, Uruguay \\ Correspondence: Bruno Irigaray, Área de Grasas y Aceites, Facultad de Química, UdelaR, Gral Flores 2124, CP \\ 11800, Montevideo, Uruguay. Tel: 598-2929-0707. E-mail: birig@ fq.edu.uy
}

Received: June 26, 2017

Accepted: August 4, 2017 Online Published: August 21, 2017

doi:10.5539/jfr.v6n5p59

URL: https://doi.org/10.5539/jfr.v6n5p59

\begin{abstract}
Extra virgin olive oil is recognized as a very stable oil because of its composition in fatty acids and its content in natural antioxidants (tocopherols and polyphenols). In the bibliography are works that address different aspects of this stability, from the duration of its useful life to its performance in the frying of foods. Some works also link their stability with the content of natural antioxidants. For example, Franco et al. (2014) studied the content of phenols and their antioxidant capacity in olive oils of seven different varieties. Baccouri et al. (2008) found a good correlation between the oxidative stability (measured in Rancimat) of the oils studied and the concentration of total phenols and tocopherols.
\end{abstract}

Keywords: Extra virgin olive oil, autoxidation, oxidative stability, thermoxidation

\section{Introduction}

Extra virgin olive oil is recognized as a very stable oil because of its composition in fatty acids and its content in natural antioxidants (tocopherols and polyphenols). In the bibliography are works that address different aspects of this stability, from the duration of its useful life to its performance in the frying of foods. Some works also link their stability with the content of natural antioxidants. For example, Franco et al. (2014) studied the content of phenols and their antioxidant capacity in olive oils of seven different varieties. Baccouri et al. (2008) found a good correlation between the oxidative stability (measured in Rancimat) of the oils studied and the concentration of total phenols and tocopherols.

The useful life of the extra virgin olive oil has been studied by several authors. The most commonly used control parameters are peroxide index (primary oxidation) and ultraviolet absorbance (K232 and K270). Psomiadou and Tsimidou (2002) studied the autoxidation of extra virgin olive oil stored for 24 months as well as the content of tocopherols and polar phenols. Morello et al. (2004) studied the changes that take place in Arbequina virgin olive oils during storage for 12 months. They found that alpha-tocopherol completely disappeared during storage and that total phenols dropped significantly. Gómez-Alonso et al. (2007) studied the evolution of the minor components and the oxidation rates of virgin olive oils of Cornicabra with different tocopherols and polyphenols contents during 21 months of storage at room temperature in the dark. The reduction of the total phenols was between $43 \%$ and $73 \%$ and its reduction was greater in the samples whose initial content of phenols was higher. Mancebo-Campos et al. (2014) studied the activity of some antioxidants in a purified olive oil, stored at $25{ }^{\circ} \mathrm{C}$ and $40{ }^{\circ} \mathrm{C}$ noting that tocopherol behaved as a pro-oxidant at the temperatures studied.

Other authors studied the oxidative stability of olive oils stored at temperatures above ambient. Hrncirik and Fritsche (2005) studied the antioxidants and quality of extra virgin oils of the Koroneiki, Coratina and Picual varieties stored at $60{ }^{\circ} \mathrm{C}$ in the dark. Stability was determined by the peroxide index; correlated these values with the OSI index determined at $100{ }^{\circ} \mathrm{C}$ and the content and composition of phenols and tocopherols. On the one hand they found that the higher the antioxidant content of oils, the longer their OSI times. On the other hand, the stability ratios of the oils were maintained with respect to the increase of their peroxide index and the ultraviolet absorbance (K232 and K270) with the heating time. Lerma-García et al. (2009) studied the chemical changes of a sample of extra virgin olive oil in the presence and absence of its phenolic fraction during accelerated storage at $60{ }^{\circ} \mathrm{C}$ for 7 weeks, they observed an increased of the oxidized products with decreased of the antioxidants.

Thermoxidation changes in oils during the frying of foods or in the absence of food could be very different from those of autoxidation. In the autoxidation there is an increase in the peroxide index and the ultraviolet 
absorbance (K232 and K270). In the thermoxidation there is no increase in the peroxide index because these are very unstable at high temperatures, so that the formation of polar compounds predominates. Many countries have regulations regarding the maximum permissible content of polar compounds in oils used in repeated frying of foods. Velasco and Dobarganes (2002) studied virgin olive oil during storage and at high temperature (frying and baking). They discussed the differences between low and high temperature mechanisms.

The thermoxidation of the oil in the absence of food and without bubbling of air in them was studied by several authors. Valdés and García (2006) studied the evolution of physico-chemical parameters at $150{ }^{\circ} \mathrm{C}$ and $225{ }^{\circ} \mathrm{C}$ for 1-15 days. Carrasco-Pancorbo et al. (2007) evaluated the influence of the composition of the antioxidants on oxidative stability and its deterioration by the thermoxidation of the oil at $180^{\circ} \mathrm{C}$. Mancebo-Campos et al. (2007) studied the oxidation under accelerated conditions in a Rancimat apparatus compared with storage at room temperature $\left(25^{\circ} \mathrm{C}\right)$ for a long period. They found a lack of correlation between the results of induction times and storage at room temperature. They also found that polyphenols and tocopherols were rapidly degraded under such thermoxidation conditions. Maggio et al. (2011) studied three samples of extra virgin olive oil subjected to heating at $180^{\circ} \mathrm{C}$ in the oven for $30,60,90,120,150$ and 180 minutes.

Studies on the thermoxidation of oils in the absence of food but with bubbling of air are also found in the literature. Bester et al. (2008) studied the behavior of 7 samples of extra virgin olive oil in a Rancimat equipment at $100{ }^{\circ} \mathrm{C}$ and with air bubbles of $10 \mathrm{~L} / \mathrm{h}$ for 142 hours. After that treatment the tocopherols disappeared completely and the total content of biophenols dropped to about half. Campanella et al. (2008) studied the atmospheric oxidation at different temperatures $\left(98,120,140,160\right.$ and $\left.180{ }^{\circ} \mathrm{C}\right)$ with air bubbling. The almost total disappearance of phenols occurred at increasingly shorter times as the temperature increased.

Discontinuous frying of potatoes is often used as a model to study the behavior of oils since they do not contribute lipids to the medium. Silva et al. (2010) studied the frying of potatoes in olive oil for 60 minutes at $180{ }^{\circ} \mathrm{C}$, in the absence and presence of food. All the components of the polyphenols decreased their concentration with the heat treatment and that decrease was much greater in the presence of food. Casal et al. (2010) studied the frying of potatoes in a domestic fryer at $170{ }^{\circ} \mathrm{C}$, until reaching a polar compound content of $25 \%$. They used an extra virgin olive oil, two virgin monovarietals and a mixture of refined oil with virgin. All these oils reached $25 \%$ of compounds in a range of 3 days but in all the oils the phenols disappeared in less than a day. They showed that in these conditions the phenols are very labile so there was no significant difference between the behavior of the different types of oils used. Santos et al. (2013) made a literature review on the effect of cooking on the different qualities of olive oil (virgin extra, virgin, refined). They found that the performance of virgin olive oil under conditions of prolonged thermal processes (frying in depth and surface, microwave, boiled, toasted) is equal to or higher than other refined vegetable oils due to its composition. As most of these bioactive compounds (including phenolic compounds) are gradually lost there are no differences in behavior between the different grades of olive oil. In addition, the polyphenols content is affected by the thermal process, but their loss depends on their molecular structure (Gómez-Alonso et al., 2003; Carrasco-Pancorbo et al., 2007; Cheikhousman et al., 2005; Daskalaki et al., 2009; Romero et al., 2003).

In conclusion, most of the works consulted refer to the stability of the extra virgin olive oil in different processes: storage at relatively low temperatures, thermoxidation at high temperatures and frying of foods. Many of them also determine the deterioration of their antioxidants. No studies were found that, with the same extra virgin olive oils, their stability is compared in all those processes that lead to such different mechanisms of deterioration.

On the other hand, the OSI induction period is generally used as an index of stability of the oils. However, this is determined under certain operating conditions (with air bubbling and generally at $110{ }^{\circ} \mathrm{C}$ ) which are very different from those of storage at room temperature or food frying at $180{ }^{\circ} \mathrm{C}$. It is therefore important to determine the applicability of these results in different deterioration situations.

The aim of this work was to evaluate the behavior of two extra virgin monovarietal oils (Coratina and Arbequina, with a very different content of polyphenols) compared to storage at room temperature, storage at $60{ }^{\circ} \mathrm{C}$, thermoxidation at $180^{\circ} \mathrm{C}$ and fry at $180^{\circ} \mathrm{C}$. These results are also compared with oxidative stability at $110{ }^{\circ} \mathrm{C}$ as determined by induction time (OSI).

\section{Materials and Methods}

\subsection{Raw Materials}

Monovarietal extra virgin olive oils from Arbequina and Coratina, from Uruguayan industrial processing (Finca Babieca, Maldonado, Uruguay). 


\subsection{Thermal Study}

Storage at room temperature and $60^{\circ} \mathrm{C}$ :

The oils were packed in amber bottles (volume, $100 \mathrm{~mL}$ and surface/volume ratio, $0.05 \mathrm{~cm}^{-1}$ ). One bottle group was stored at $25^{\circ} \mathrm{C}$ for 40 weeks and another group was stored at $60^{\circ} \mathrm{C}$ for 7 weeks. During that period, a weekly sample (one bottle) of each of the oils was analyzed. Once this sample was taken, the rest of the oil contained in the bottle was discarded. Samples were stored at $-20^{\circ} \mathrm{C}$ until analysis.

Thermoxidation of oils:

The oils (quantity: 600 grams) were placed in Bohemia glasses of $1 \mathrm{~L}$. Surface/volume ratio of the oil: 0.087 $\mathrm{cm}^{-1}$. To heat them were used heating plates with magnetic stirrer. The oil was heated at $180{ }^{\circ} \mathrm{C}$ for 1 hour, cooled to $120^{\circ} \mathrm{C}$ and reheated to $180^{\circ} \mathrm{C}$. These cycles were repeated for a total of 20 hours. Small samples of 1 $\mathrm{g}$ of oil were removed every 5 hours (the small size of the sample does not significantly alter the initial surface / volume ratios of the oil). Samples were stored at $-20^{\circ} \mathrm{C}$ until analysis.

\subsection{Discontinuous Frying of Potatoes}

The potatoes were peeled, washed and cut into parallelepipeds of similar size (canes). They were fried in batches of $100 \mathrm{~g}$ in $300 \mathrm{~g}$ of oil (ratio 1:3). The frying tests with the two types of oil were carried out simultaneously using two identical frying pan, with a surface to volume ratio of approx. $1.5 \mathrm{~cm}^{-1}$.

The initial frying temperature, in all cases, was $180^{\circ} \mathrm{C}$. Twenty frying operations were carried out for 4 minutes each (80 minutes in total). Each frying operation was performed with the same amount of oil because the oil lost in the previous frying was recovered (determined by weighing before and after the frying).

At the end of each frying, the oil was cooled at room temperature and a sample of $1 \mathrm{~g}$ of oil was withdrawn. The samples were stored at $-20^{\circ} \mathrm{C}$ until analyzed.

\subsection{Analytical Determinations}

The Polyphenols were determined by High Resolution Liquid Chromatography (HPLC). Column type C18 (length $250 \mathrm{~mm}$, diameter $4.6 \mathrm{~mm}$, particle size $5 \mu \mathrm{m}$ ). Solvent system: acetonitrile, methanol, phosphoric acid $0.2 \%$ - water. Analysis time: 82 minutes. Method IOC / T.20 / DOC 29, November 2009.

The content of tocopherols was determined by HPLC according to the method described in Andrikopolus et al. (1991).

The Total polar compound content was determined analyzed by Standard method IUPAC 2.507 . They were determined in duplicate.

The Acidity was determined by Standard method IUPAC 2.201. They were determined in duplicate.

The Peroxide index was determined by Standard method IUPAC 2.501. They were determined in duplicate.

The p-anisidine index was determined by Standard method IUPAC 2.504. They were determined in duplicate.

The Absorbance in ultraviolet (K232 and K270) were determined by Method COI / T.20 / Doc. No 19 / Rev. 3, "Spectrophotometric investigation in the ultraviolet". They were determined in duplicate.

The Oxidation stability index at $110{ }^{\circ} \mathrm{C}$ (OSI induction times) was determined by Standard method AOCS Cd-12b-92. They were determined in triplicate.

The determination of fatty acids composition was made by derivatization of the triglycerides to methyl esters by the standard method AOCS Ch 1-91 and its subsequent analysis by gas chromatography, standard method AOCS Ce 1e-91.

\section{Results and Discussion}

\subsection{Characterization of the Raw Materials: Extra Virgin Oils of Arbequina and Coratina}

The characteristics of the oils studied are shown in Table 1.

The peroxide index, the acidity and the absorbance to the ultaviolet (K232 and K270) of the two oils were similar so that the two oils can be considered of the same quality. The p-anisid index indicated that both oils were at a similar level of secondary oxidation.

Regarding to fatty acid composition, Coratina oil has more oleic acid and less linoleic acid than Arbequina oil (Table 1) and, hence it is expected that the oil of Coratina is more stable to the oxidation. The Arbequina oil has an inherent stability of 2.1 and this Coratina oil, 1.7. By means of the inherent stability, it is possible to estimate the effect of the composition on fatty acids on their resistance to oxidation. The inherent stability number of a 
fatty material is defined in terms of the relative oxidation rates of the unsaturated fatty acids at $37{ }^{\circ} \mathrm{C}$ and their percentage content. Smaller is the number, greater is the stability of the fatty material. Reference is made to the value 1 for the oxidation rate of oleic acid; as a function of it linoleic acid has a relative velocity of 10 and linolenic of 25 (Gunstone and Hilditch, 1946; Erickson and List, 1985).

The OSI times at $110{ }^{\circ} \mathrm{C}$ were very different since the Coratina oil was 2.4 times higher than that of the Arbequina oil, which could indicate a greater resistance to the oxidation of the Coratina oil. This is linked to their different contents of antioxidants since they do not differ significantly in their composition in fatty acids. Coratina oil has $18 \%$ more tocopherols than Arbequina oil as well as triple polyphenols. As in this work, Baccouri et al. (2008) found a good correlation between the oxidative stability (measured in Rancimat) of the oils studied and the concentration of total phenols and tocopherols.

Table 1. Characterization of virgin olive oils of the Arbequina and Coratina varieties

\begin{tabular}{lll}
\hline & Arbequina & Coratina \\
\hline Acidity (\%) & $0.16 \pm 0.01$ & $0.14 \pm 0.01$ \\
Peroxide index & $4.4 \pm 0.1$ & $4.2 \pm 0.2$ \\
K232 & $1.54 \pm 0.15$ & $1.33 \pm 0.13$ \\
K270 & $0.102 \pm 0.015$ & $0.082 \pm 0.012$ \\
p-anisidine index & $4.3 \pm 0.1$ & $5.9 \pm 0.1$ \\
Tocopherols (ppm) & $174 \pm 9$ & $205 \pm 10$ \\
Polyphenols (ppm) & $129 \pm 6$ & $389 \pm 19$ \\
OSI time (h) at $110{ }^{\circ} \mathrm{C}$ & $11.7 \pm 0.8$ & $28.2 \pm 0.3$ \\
Polar compound $(\%)$ & $3 \pm 1$ & $2 \pm 1$ \\
\hline Fatty acid composition $(\%)$ & \\
\hline $16: 0$ & 14.0 & 10.1 \\
$16: 1$ & 1.3 & 0.4 \\
$18: 0$ & 1.6 & 1.8 \\
$18: 1$ & 70.2 & 80.0 \\
$18: 2$ & 11.7 & 6.3 \\
$18: 3$ & 0.9 & 1.1 \\
\hline
\end{tabular}

\subsection{Storage at Room Temperature}

The results obtained for the peroxide index and the ultraviolet absorbance (K232 and K270) are given in Table 2 as a function of the storage time of the oils at room temperature $\left(25^{\circ} \mathrm{C}\right)$ and protected from light. As in general, extra virgin olive oils are given one-year expiration, from week 13 it was passed to week 40 as a way to study that period.

The IOC 2015 standard establishes limits for the extra virgin olive oils: K232 $\leq 2.50$, K $270 \leq 0.22$, peroxide index $\leq 20$. Therefore, Arbequina oil at week 13 had lost its quality of Extra virgin according to the value of K232 and at week 40 according to its peroxide index. Coratina oil had lost its extra virgin status in week 40, both for its K232 and for its peroxide index. However, at week 40 Arbequina oil had a higher peroxide index (41.23) than Coratina oil (36.98). On the other hand, the K232, K270 and the peroxide index of the Coratina oil were always smaller than the corresponding ones of the Arbequina oil. These findings indicate a lower rate of oxidative deterioration at room temperature of the Coratina oil compared to the Arbequina oil, that is to say, a slightly longer shelf-life. From the OSI times determined it was expected that the Coratina oil would be more stable than Arbequina, but since the ratio of the induction periods was 2.4 times it was also expected that the differences in stability at room temperature would be more pronounced (which would also be justified by the differences in the initial contents of antioxidants of the two oils). Baccouri et al. (2008) found a good correlation between the stability determined in Rancimat and the concentration of polyphenols and tocopherols.

The tocopherols content of both oils decreased considerably during storage to $22 \%$ in the Coratina oil and to $24 \%$ in the Arbequina oil (Table 2). Although the initial tocopherols content of Coratina oil was 1.2 times higher than that of Arbequina oil, after 40 weeks their ratio only decreased to 1.1 . Therefore, as the first 11 weeks of storage passed, the oils lost tocopherols at a similar ratio.

The polyphenol content of both oils also decreased considerably during storage to $27 \%$ in Coratina oil and $36 \%$ in Arbequina oil (Table 2). That as to say, the polyphenol content decreased more rapidly in the oil with the higher initial concentration of polyphenols, similar conclusion to that obtained by Gómez-Alonso et al. (2007). 
In spite of this, the polyphenol content of Coratina oil was always higher than that of Arbequina oil. This could explain the greater stability of Coratina oil.

These results agree with those found by Morello et al. (2004), where the alpha-tocopherol disappeared completely and the total phenols decreased significantly during 12 months of storage. Conversely, Psomiadou and Tsimidou (2002) observed that the losses of tocopherols and polyphenols were similar after 24 months of storage. This is probably because the oils were different and that such oxidation studies were not done exactly under the same conditions.

Table 2. Evolution of peroxide index, K232 and K270 of the virgin olive oils of the Arbequina and Coratina varieties as a function of the storage time at $25^{\circ} \mathrm{C}$

\begin{tabular}{llllll}
\hline & initial & week 5 & week 9 & week 13 & week 40 \\
\hline Arbequina & & & & & \\
\hline Peroxide index & $4.4 \pm 0.2$ & $7.5 \pm 0.3$ & $14.2 \pm 0.5$ & $17.5 \pm 0.5$ & $41.2 \pm 0.7$ \\
K232 & $1.54 \pm 0.15$ & $1.81 \pm 0.18$ & $2.40 \pm 0.24$ & $2.42 \pm 0.24$ & $5.06 \pm 0.51$ \\
K270 & $0.102 \pm 0.015$ & $0.094 \pm 0.014$ & $0.095 \pm 0.014$ & $0.116 \pm 0.017$ & $0.161 \pm 0.024$ \\
Tocopherols (ppm) & $174 \pm 9$ & $86 \pm 4$ & $61 \pm 3$ & $52 \pm 2$ & $42 \pm 2$ \\
Polyphenols (ppm) & $129 \pm 6$ & $123 \pm 6$ & $89 \pm 4$ & $94 \pm 5$ & $47 \pm 2$ \\
\hline Coratina & \multicolumn{5}{c}{} \\
\hline Peroxide index & $4.2 \pm 0.2$ & $3.5 \pm 0.2$ & $8.1 \pm 0.3$ & $15.0 \pm 0.2$ & $37.0 \pm 0.7$ \\
K232 & $1.33 \pm 0.13$ & $1.65 \pm 0.17$ & $1.61 \pm 0.16$ & $1.64 \pm 0.16$ & $2.90 \pm 0.29$ \\
K270 & $0.082 \pm 0.012$ & $0.090 \pm 0.014$ & $0.132 \pm 0.020$ & $0.138 \pm 0.021$ & $0.134 \pm 0.020$ \\
Tocopherols (ppm) & $205 \pm 10$ & $180 \pm 9$ & $119 \pm 6$ & $84 \pm 4$ & $46 \pm 2$ \\
Polyphenols (ppm) & $389 \pm 19$ & $215 \pm 11$ & $213 \pm 11$ & $228 \pm 11$ & $106 \pm 5$ \\
\hline
\end{tabular}

\subsection{Storage at $60^{\circ} \mathrm{C}$.}

The results obtained for the peroxide index and the ultraviolet absorbance (K232 and K270) are given in Table 3, as a function of the storage time at a temperature of $60^{\circ} \mathrm{C}$ in the absence of light.

The data show that the rate of the increase of the peroxide index was higher for the Arbequina oil than for the Coratina oil. Because of this, at 6 weeks Arbequina oil had a peroxide index of almost 40 while at 10 weeks the peroxide index of Coratina oil was only about 25 . Therefore, under accelerated conditions at $60{ }^{\circ} \mathrm{C}$, Coratina oil was much more stable than Arbequina oil. Similar conclusions are drawn regarding K232 and K270. This is consistent with the stability determined by the OSI times for the initial oils.

The decrease in the concentration of tocopherols and polyphenols in both oils produced in 8 weeks storage at $60{ }^{\circ} \mathrm{C}$ could be seeing in Table 3 .

Table 3. Evolution of the index of proxies, K232 and K270 of the virgin olive oils of the varieties Arbequina and Coratina as a function of storage time at $60^{\circ} \mathrm{C}$

\begin{tabular}{|c|c|c|c|c|c|c|c|c|c|c|}
\hline & initial & 2 & 3 & 4 & 5 & 6 & 7 & 8 & 9 & 10 \\
\hline \multicolumn{11}{|l|}{ Arbequina } \\
\hline Peroxide index & $4.4 \pm 0.1$ & $14.5 \pm 0.5$ & $22.1 \pm 0.7$ & $23.8 \pm 0.8$ & $34.4 \pm 0.3$ & $39.9 \pm 0.3$ & - & - & - & - \\
\hline K232 & $1.54 \pm 0.15$ & $3.01 \pm 0.30$ & $3.69 \pm 0.37$ & $3.58 \pm 0.36$ & $5.93 \pm 0.59$ & - & - & - & - & - \\
\hline K270 & $0.102 \pm 0.015$ & $0.145 \pm 0.022$ & $0.177 \pm 0.027$ & $0.174 \pm 0.026$ & $0.242 \pm 0.036$ & $0.372 \pm 0.056$ & - & - & - & - \\
\hline Tocopherols(ppm) & $174 \pm 9$ & $162 \pm 8$ & $166 \pm 8$ & $111 \pm 6$ & $48 \pm 2$ & 0 & - & - & - & - \\
\hline Polyphenols(ppm) & $144 \pm 7$ & $133 \pm 7$ & $104 \pm 6$ & $94 \pm 6$ & $92 \pm 5$ & $87 \pm 4$ & - & - & - & - \\
\hline \multicolumn{11}{|l|}{ Coratina } \\
\hline Peroxide index & $4.2 \pm 0.2$ & $7.5 \pm 0.3$ & $7.7 \pm 0.3$ & $8.5 \pm 0.3$ & $8.8 \pm 0.5$ & $9.4 \pm 0.4$ & $19.5 \pm 0.7$ & $22.0 \pm 0.7$ & $22.9 \pm 0.6$ & $24.8 \pm 0.7$ \\
\hline K232 & $1.33 \pm 0.13$ & $1.90 \pm 0.20$ & $1.98 \pm 0.20$ & $2.83 \pm 0.28$ & $3.35 \pm 0.34$ & $3.36 \pm 0.34$ & - & - & - & - \\
\hline K270 & $0.082 \pm 0.012$ & $0.166 \pm 0.025$ & $0.151 \pm 0.023$ & $0.182 \pm 0.027$ & $0.154 \pm 0.023$ & $0.204 \pm 0.031$ & $0.342 \pm 0.051$ & $0.326 \pm 0.049$ & - & - \\
\hline Tocopherols(ppm) & $205 \pm 10$ & $172 \pm 9$ & $164 \pm 8$ & $151 \pm 8$ & $151 \pm 8$ & $136 \pm 7$ & $28 \pm 1$ & $7 \pm 1$ & - & - \\
\hline Polyphenols(ppm) & $389 \pm 19$ & $302 \pm 15$ & $197 \pm 10$ & $185 \pm 9$ & $182 \pm 9$ & $210 \pm 10$ & $128 \pm 6$ & $128 \pm 6$ & - & - \\
\hline
\end{tabular}


The concentration of polyphenols was always higher in Coratina oil than in Arbequina oil and never disappeared as in Arbequina oil. The same happened with the concentration of tocopherols since in week 6 the Arbequina oil lacked them. These variations of the antioxidant content explain that the Coratina oil is more stable under these conditions.

\subsection{Thermoxidation with Agitation and Without Air Bubbling}

Figure 1a shows the evolution of the content of polar compounds in both oils, as a function of the hours of heating at $180{ }^{\circ} \mathrm{C}$. Both oils exhibit practically the same behavior at thermoxidation. This was not expected considering the OSI times determined and the deterioration during storage at room temperature and at $60{ }^{\circ} \mathrm{C}$. This shows that different mechanisms take place for the oxidation of the oils under such different conditions of deterioration.

Since tocopherols rapidly deteriorated to $60^{\circ} \mathrm{C}$ and polyphenols were the most effective antioxidants in virgin olive oil, only the variation of the polyphenol content in the studies at $180{ }^{\circ} \mathrm{C}$ (thermoxidation and frying of potatoes) was determined (Table 4).

Table 4. Variation of the concentration of polyphenols and polar compounds (PC) virgin olive oils of the varieties Arbequina and Coratina at 20 hours of thermoxidation at $180^{\circ} \mathrm{C}$ and after 20 frying steps

\begin{tabular}{lllll}
\hline & arbequina & \multicolumn{2}{c}{ coratina } & \\
\hline \multicolumn{1}{c}{ polyphenols (ppm) } & PC (\%) & polyphenols (ppm) & PC (\%) \\
Initial & $129 \pm 6$ & $3 \pm 1$ & $389 \pm 19$ & $2 \pm 1$ \\
20 hours & $30 \pm 2$ & $45 \pm 1$ & $28 \pm 1$ & $46 \pm 1$ \\
20 fryings & $58 \pm 3$ & $21 \pm 1$ & $45 \pm 2$ & $21 \pm 1$ \\
\hline
\end{tabular}

a)
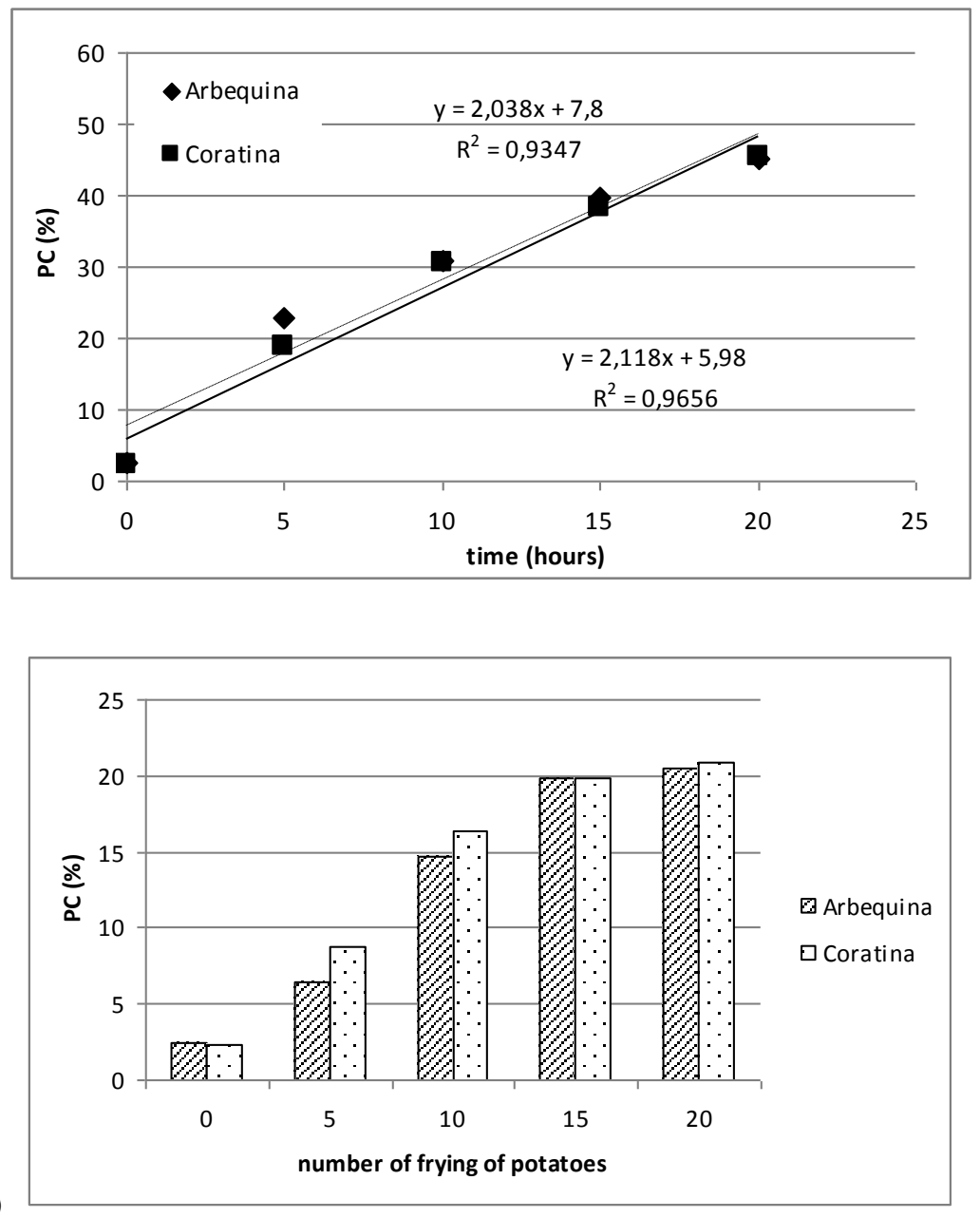

Figure 1. Evolution of the content of polar compounds (PC) in the virgin olive oils of the Arbequina and Coratina varieties as a function of a) the hours of heating at $180^{\circ} \mathrm{C}$; b) the number of frying of potatoes 
After 20 hours of thermoxidation, the polyphenol content of the Coratina oil was practically the same as for the Arbequina oil (although initially the Coratina oil had 3 times more polyphenols than the Arbequina oil). This shows that in the thermoxidation the polyphenols were degraded at different rates so that during the process their concentration reached similar values. As a result, the polyphenols failed to protect both oils, which explains that the concentration of polar compounds reached similar values.

This was not expected, according to OSI times and storage trials, in which Coratina oil was much more stable than Arbequina oil (based on increased peroxide index and K232 and K270, Tables 3 and 4). These conclusions are consistent with those of Mancebo-Campos et al. (2007) who studied the thermoxidation in a Rancimat equipment, compared with storage at $25{ }^{\circ} \mathrm{C}$. They found a lack of correlation between both results, in a similar way than in this work.

The results obtained in the present study confirm that the mechanisms of deterioration are different and that the kinetics of peroxide formation at room temperature are not the same as the formation of polar compounds at $180{ }^{\circ} \mathrm{C}$. As the oils have practically the same composition in fatty acids (their inherent stabilities are similar), these differences of behavior could be due to the accelerated deterioration of the polyphenols during the thermoxidation.

Campanella et al. (2008) studied the oxidation under bubbling air at different temperatures $\left(98{ }^{\circ} \mathrm{C}\right.$ to $180{ }^{\circ} \mathrm{C}$ ) and found that the total disappearance of the phenols occurred at shorter and shorter times as the temperature increased. Carrasco-Pancorbo et al. (2007) evaluated the influence of the polyphenols composition on the oxidative stability and its deterioration by thermoxidation at $180^{\circ} \mathrm{C}$. Although olive oil extra virgin used in both studies, their results can't be compared with this study because they determined the peroxide index of oils and not the content of polar compounds.

\subsection{Discontinuous Frying of Potatoes in Frying Pan}

Figure $1 \mathrm{~b}$ shows the increase in the content of polar compounds in the oils used for the frying of potatoes, depending on the number of frying made with them.

As fried potatoes were made, the content of polar compounds increased for both oils. After frying No. 15, a slowdown in the formation of polar compounds for both oils was observed. The decrease in the formation rate of the polar compounds when increasing the number of fryings can be due to the degradation of molecules already altered (polar). In general, Coratina oil appeared to be more unstable than Arbequina oil. This was not expected from the determined OSI times, demonstrating that the mechanisms followed for the deterioration of the oils in these two different deterioration conditions are different.

Considered only de first $15^{\text {th }}$ frying steps (before the slowing of the formation of polar compounds), is possible see that the polar compound content of Coratina was higher than that of Arbequina oil, and both oils exhibited similar rates of deterioration.

About the total content of polyphenols after 20 potato fryings in both oils (Table 4), for approximately the same content of polar compounds, the polyphenol content was slightly higher in the Arbequina oil than in the Coratina oil (starting from a Coratina oil with 3 times the content of polyphenols than the Arbequina oil). It follows that Arbequina oil reduced its polyphenol concentration to $45 \%$ while Coratina reduced it to $12 \%$. This indicates that the polyphenols of the Coratina oil were degraded at a higher rate than the polyphenols of the Arbequina oil (phenomenon similar to the one found in this work for the temoxidation). This degradation indicates that the protection coming from them was reduced drastically with the number of fryings. Possibly because of this, both oils simultaneously reached the same $\%$ polar.

Casal et al. (2010) studied the frying of potatoes at $170{ }^{\circ} \mathrm{C}$. The phenols disappeared after a few hours of frying (between 6 and 9 hours), the results are not completely compatible with the present study since the methodology used for the measurement of the phenols was not the same.

\subsection{Comparison of the Four Processes of Deterioration}

The peroxide index increased much more rapidly in the oil at $60^{\circ} \mathrm{C}$ than at room temperature (Tables 2 and 3 ). This is expected according to the acceleration caused by the increase in temperature.

On the other hand, at week 40 at room temperature, the ratio of the peroxide index of the Arbequina oil to that of the Coratina oil was $41.23 / 36.98=1.1$ while at week 6 at $60{ }^{\circ} \mathrm{C}$ the ratio was $39.94 / 9.41=4.2$. This means that the acceleration of deterioration due to temperature increase was not the same for both oils.

Both tocopherols and polyphenols deteriorated more slowly in 5 weeks at room temperature than at $60{ }^{\circ} \mathrm{C}$. This justifies that shelf-life under accelerated conditions is so much shorter than room temperature. 
Both at room temperature and at $60{ }^{\circ} \mathrm{C}$, the highest deterioration rate of polyphenols (pending the respective trend lines) corresponds to Coratina oil (which has the highest initial polyphenol content). As a result, the rate of deterioration of each polyphenol depends on its initial concentration, so higher initial concentration, higher rate of deterioration, as indicated by Gómez-Alonso et al. (2007).

In the tests at $180{ }^{\circ} \mathrm{C}$ (thermoxidation and frying of potatoes) the behavior of the oils was very different: both deteriorated at the same rate (according to the formation of polar compounds).

Under conditions of thermoxidation at $180{ }^{\circ} \mathrm{C}$ (in the absence of food) or during repeated frying of potatoes at $180{ }^{\circ} \mathrm{C}$, the formation of polar compounds determines their possibility of re-use. This follows very different mechanisms from the primary oxidation (peroxide formation) of oil stored under ambient conditions or at $60{ }^{\circ} \mathrm{C}$.

These differences in behavior are also related to the deterioration of the polyphenols present. The polyphenols (ppm) content of both oils are shown in Figure 2 for the four tests performed: after 40 weeks storage at room temperature, after 6 weeks storage at $60{ }^{\circ} \mathrm{C}$, after 20 hours of thermoxidation at $180{ }^{\circ} \mathrm{C}$ and after 20 frying of potatoes at $180{ }^{\circ} \mathrm{C}$.

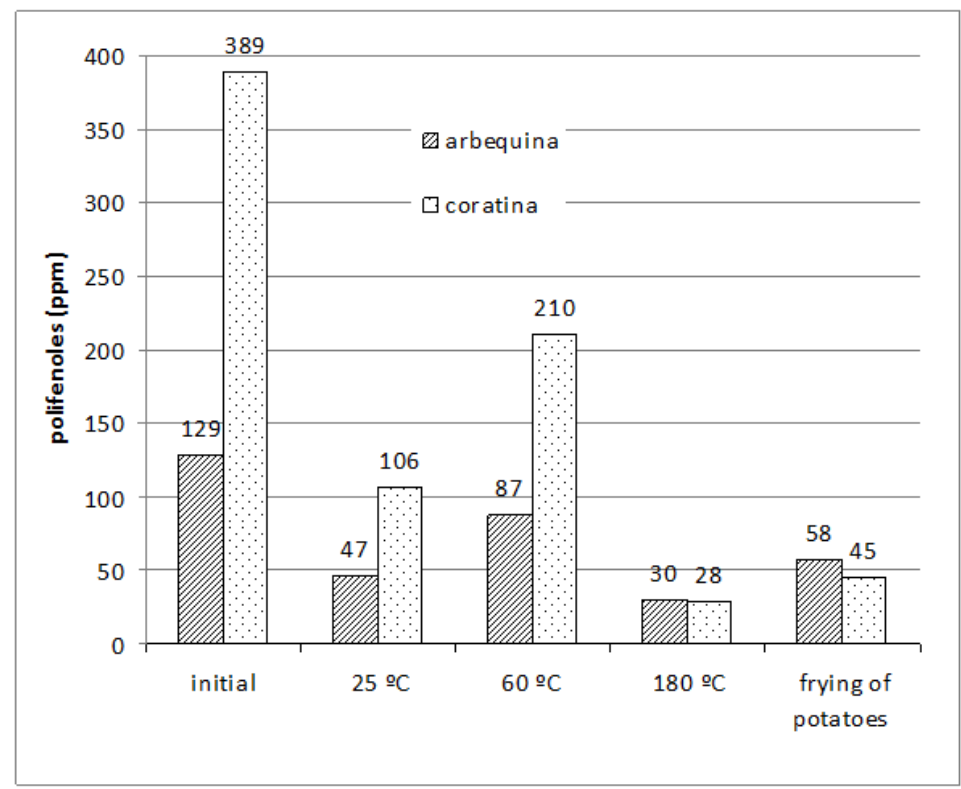

Figure 2. Polyphenol content (ppm) of the virgin olive oils of the Arbequina and Coratina varieties for the four tests performed: after 40 weeks of storage at $25^{\circ} \mathrm{C}$, after 6 weeks of storage at $60^{\circ} \mathrm{C}$, after 20 hours of thermoxidation at $180^{\circ} \mathrm{C}$ and after 20 frying of potatoes at $180^{\circ} \mathrm{C}$

The 20 frying of potatoes (each of 4 minutes) at $180^{\circ} \mathrm{C}$ correspond to a total of 80 minutes. The thermoxidation of the oil at $180^{\circ} \mathrm{C}$ was 20 hours. Although the final content of polyphenols was slightly higher in the oil used for frying potatoes, given the very large difference in heating times it can be deduced that the deterioration of polyphenols is bigger when there is potato (frying) than in their absence (thermoxidation). These results are consistent with those found by Silva et al. (2010) because they found that all the polyphenols components decreased their concentration with the heat treatment and that decrease was drastic in the presence of food.

There is a noticeable difference in behavior between oils stored at room temperature and at $60{ }^{\circ} \mathrm{C}$ with oils kept at $180^{\circ} \mathrm{C}$ (thermoxidation) or used in frying potatoes at $180^{\circ} \mathrm{C}$. Coratina oil with a high content of polyphenols is more protected against oxidation (depending on, for example, its peroxide index) at relatively low temperatures than at high temperatures where polyphenols degrade and fail to protect it (with a mechanism of preponderant polar formation deterioration and not of peroxide formation). At moderate temperature conditions, OSI index is indicative of the stability of the oil, but in similar conditions to frying of foods, tocopherols and polyphenols which deteriorate rapidly, stops being.

\section{Conclusions}

The OSI times do not reflect the order of stability of the oils under thermoxidation conditions at $180{ }^{\circ} \mathrm{C}$ or in the frying of potatoes at the same temperature, where the formation of polar compounds determines their use. In contrast, OSI times are indicative for comparison of shelf-life of oils where the mechanisms of formation of 
primary oxidation compounds predominate. However, without air bubbling and at these low temperatures $\left(20-30^{\circ} \mathrm{C}\right)$ with respect to the OSI test temperature $\left(110^{\circ} \mathrm{C}\right)$ the quantitative stability ratios are not maintained.

The antioxidants are deteriorated at very different rates depending on the experimental conditions. Thus, at high temperatures, in the absence or presence of food, antioxidants disappear quickly, failing to protect oils. Therefore, the initial antioxidant content of an extra virgin olive oil has little relevance to its use in repeated frying of food (the fatty acid composition of the oil is probably more important, so an olive oil will be more stable than other more polyunsaturated oils).

\section{References}

Andrikopoulos, N. K, Brueschweiler, H., Felber, H., \& Taeschler, Ch. (1991). HPLC analysis of phenolic antioxidants, tocopherols and triglycerides. J. Am. Oil Chem. Soc., 68, 359-364. https://doi.org/10.1007/BF02663750

AOCS. (1990). Official Methods and Recommended Practices of the American Oil Chemists' Society. (4th ed.). Champaign, USA.

Baccouri, O., Guerfel, M., Baccouri, B., Cerretani, L., Bendini, A., Lercker, G., Zarrouk, M., \& Ben Miled, D. D. (2008). Chemical composition and oxidative stability of Tunisian monovarietal virgin olive oils with regard to fruit ripening. Food Chemistry, 109, 743-754. https://doi.org/10.1016/j.foodchem.2008.01.034

Bester, E., Butinar, B., Bucar-Miklavcic, M., \& Golob, T. (2008). Chemical changes in extra virgin olive oils from Slovenian Istra after thermal treatment. Food Chemistry, 108, 446-454. https://doi.org/10.1016/j.foodchem.2007.10.061

Campanella, L., Nuccilli, A., Tomassetti, M., \& Vecchio, S. (2008). Biosensor analysis for the kinetic study of polyphenols deterioration during the forced thermal oxidation of extra-virgin olive oil. Talanta, 74, 1287-1298. https://doi.org/10.1016/j.talanta.2007.08.036

Carrasco-Pancorbo, A., Cerretani, L., Bendini, A., Segura-Carretero,A., Lercker, G., \& Fernández-Gutiérrez, A. (2007). Evaluation of the Influence of Thermal Oxidation on the Phenolic Composition and on the Antioxidant Activity of Extra-Virgin Olive Oils. J. Agric. Food Chem., 55, 4771-4780. https://doi.org/10.1021/jf070186m

Casal, S., Malheiro, R., Sendas, A., Oliveira, B. P. P., \& Pereira, J. A. (2010). Olive oil stability under deep-frying conditions. Food and Chemical Toxicology, 48, 2972-2979. https://doi.org/10.1016/j.fct.2010.07.036

Cheikhousman, R., Zude, M., Bouveresse, D. J. R., Léger, C. L., Rutledge, D. N., \& Birlouez-Aragon, I. (2005). Fluorescence spectroscopy for monitoring deterioration of extra virgin olive oil during heating. Analytical and Bioanalytical Chemistry, 382, 1438-1443. https://doi.org/10.1007/s00216-005-3286-1

Daskalaki, D., Kefi, G., Kotsiou, K., \& Tasioula-Margari, M. (2009). Evaluation of phenolic compounds degradation in virgin olive oil during storage and heating. Journal of Food and Nutrition Research, 48, $31-41$.

Erickson, D. R., \& List, G. R. (1985). Storage, handling, and stabilization of edible fats and oils, Vol. III. in T. H. Applewhite (ed.) Bailey's Industrial Oil and Fat Products. John Wiley \& Sons, New York.

Franco, M. N., Galeano-Díaz, T., Sánchez, J., De Miguel, C., \& Martín-Vertedor, D. (2014). Antioxidant capacity of the phenolic fraction and its effect on the oxidative stability of olive oil varieties grown in the southwest of Spain. Grasas y Aceites, 65(1). https://doi.org/10.3989/gya.051513

Gómez-Alonso, S., Fregapane, G., Salvador, M. D., \& Gordon, M. H. (2003). Changes in phenolic composition and antioxidant activity of virgin olive oil during frying. Journal of Agricultural and Food Chemistry, 51, 667-672. https://doi.org/10.1021/jf025932w

Gómez-Alonso, S., Mancebo-Campos, V., Salvador, M. D., \& Fregapane, G. (2007). Evolution of major and minor components and oxidation índices of virgin olive oil during 21 months storage at room temperature. Food Chemistry, 100, 36-42. https://doi.org/10.1016/j.foodchem.2005.09.006

Gunstone, F. D., \& Hilditch, T. P. (1945). The union of gaseous oxygen with methyloleate, linoleate and linolenate. J. Chem. Soc., 836-841. https://doi.org/10.1039/jr9450000836

Hrncirik, K., \& Fritsche, S. (2005). Relation between the Endogenous Antioxidant System and the Quality of Extra Virgin Olive Oil under Accelerated Storage Conditions. J. Agric. Food Chem. 53, 2103-2110. https://doi.org/10.1021/jf048363w 
IOC (Internacional Olive Council). (2015). Chemistry/Testing Methods/Chemical testing methods, http://www.internationaloliveoil.org/.

IOC (Internacional Olive Council). (2015). Trade Standard Applying to Olive Oils and Olive-Pomace Oils.COI/T.15/NC nº 3/Rev. 9.

IUPAC. (1992). Standard methods for the analysis of oils, fats and derivatives. International Union of Pure and Applied Chemistry. 1st supplement to 7th edition, Pergamon Press, Oxford.

Lerma-García, M. J., Simó-Alfonso, E. F., Chiavaro, E., Bendini, A., Lercker, G., \& Cerretani, L. (2009). Study of Chemical Changes Produced in Virgin Olive Oils with Different Phenolic Contents during an Accelerated Storage Treatment. J. Agric. Food Chem., 57, 7834-7840. https://doi.org/10.1021/jf901346n

Maggio, R. M., Valli, E., Bendini, A., Gómez-Caravaca, A. M., Toschi, T. G., \& Cerretani, L. (2011). A spectroscopic and chemometric study of virgin olive oils subjected to thermal stress. Food Chemistry, 127, 216-221. https://doi.org/10.1016/j.foodchem.2010.12.018

Mancebo-Campos, V., Salvador, M. D., Fregapane, G. (2007). Comparative Study of Virgin Olive Oil Behavior under Rancimat Accelerated Oxidation Conditions and Long-Term Room Temperature Storage. J. Agric. Food Chem., 55, 8231-8236. https://doi.org/10.1021/jf070915y

Mancebo-Campos, V., Salvador, M. D., \& Fregapane, G. (2014). Antioxidant capacity of individual and combined virgin olive oil minor compounds evaluated at mild temperature $\left(25\right.$ and $\left.40{ }^{\circ} \mathrm{C}\right)$ as compared to accelerated and antiradical assays. Food Chemistry, 150, 374-381. https://doi.org/10.1016/j.foodchem.2013.10.162

Morelló, J.-R., Motilva, M.-J., Tovar, M.-J., \& Romero, M. P. (2004). Changes in commercial virgin olive oil (cv Arbequina) during storage, with special emphasis on the phenolic fraction. Food Chemistry, 85, 357-364. https://doi.org/10.1016/j.foodchem.2003.07.012

Psomiadou, E., \& Tsimidou, M. (2002). Stability of Virgin Olive Oil. 1. Autoxidation Studies. J. Agric. Food Chem., 50, 716-721. https://doi.org/10.1021/jf0108462

Romero, A., Cuesta, C., \& Sánchez-Muniz, F. J. (2003). Cyclic FA monomers in high-oleic acid sunflower oil and extra virgin olive oil used in repeated frying of fresh potatoes. Journal of the American Oil Chemists' Society, 80, 437-442. https://doi.org/10.1007/s11746-003-0717-x

Santos, C. S. P., Cruz, R., Cunha, S. C., \& Casal, S. (2013). Effect of cooking on olive oil quality attributes. Food Research International, 54, 2016-2024. https://doi.org/10.1016/j.foodres.2013.04.014

Silva, L., Pinto, J., Carrola, J., \& Paiva-Martins, F. (2010). Oxidative stability of olive oil after food processing and comparison with other vegetable oils. Food Chemistry, 121, 1177-1187. https://doi.org/10.1016/j.foodchem.2010.02.001

Valdés, A. F., \& Garcia, A. B. (2006) A study of the evolution of the physicochemical and structural characteristics of olive and sunflower oils after heating at frying temperatures. Food Chemistry, 98, 214-219. https://doi.org/10.1016/j.foodchem.2005.05.061

Velasco, J., \& Dobarganes, C. (2002). Oxidative stability of virgin olive oil. Eur. J. Lipid Sci. Technol, 104, 661-676. https://doi.org/10.1002/1438-9312(200210)104:9/10<661::AID-EJLT661>3.0.CO;2-D

\section{Copyrights}

Copyright for this article is retained by the author(s), with first publication rights granted to the journal.

This is an open-access article distributed under the terms and conditions of the Creative Commons Attribution license (http://creativecommons.org/licenses/by/4.0/). 